\title{
Study on the Relationship Between Musculoskeletal Disorders, BDNFGene, TPH-2 Gene, and Mental Health in Coal Mine Workers in China
}

\section{Ting Jiang}

Xinjiang Medical University

Xue Li

Xinjiang Medical University

Qiaoyun Xue

The First Affiliated Hospital of Xinjiang Medical University

Jiwen Liu ( $\square$ liujiwen123123@126.com )

Xinjiang Medical University

\section{Research Article}

Keywords: mental health, musculoskeletal disorders, BDNF gene, TPH-2 gene

Posted Date: September 14th, 2021

DOI: https://doi.org/10.21203/rs.3.rs-778258/v1

License: (a) This work is licensed under a Creative Commons Attribution 4.0 International License. Read Full License 


\section{Abstract}

Background: Coal is the core energy source of the global energy system. To ensure the sustainable development of the coal industry, the mental health of coal miners is crucial.

Methods: This cross-sectional study was conducted between August 2018 and June 2019. A total of 1,675 coal miners were surveyed using the Musculoskeletal Disorders (MSDs) Questionnaire and the Symptom Checklist-90 (SCL-90). At the same time, polymorphisms in the BDNF gene ( $r$ 6265, rs10835210) and TPH2 gene (rs4570625, rs4131347) in whole blood DNA were detected to analyze the influence of a geneenvironment interaction on mental health.

Results: The results showed that the mental health status of coal miners was poorer than the Chinese norm ( $P$ $<0.05$ ). The mental health status of workers with MSDs was lower; MSDs interact with the BDNF gene rs6265 and TPH2 gene rs4570625, which affects mental health.

Conclusions: It is suggested that employers should improve the working environment of workers, shorten the working time, pay attention to the mental health of workers, and provide timely psychological counseling to workers who suffer from mental health problems, so as to improve workers' mental health and working ability, as well as their quality of life.

\section{Background}

Mental health is an important part of human health. Without good psychological health, a healthy life is not possible. In recent years, the global mental health movement developed rapidly, and the level of social attention that is paid to mental health has reached new heights. Researchers have carried out studies to examine various factors related to the mental health of teachers, police, medical personnel, and other groups [1-3]. Studies have shown that the mental health of the occupational population is not optimal due to poor work environments and work-related stress[4].

In addition to demographic characteristics, the working and living environment, and other factors affecting mental health, studies have found that the effect of gene polymorphisms on mental health cannot be ignored [5]. Brain-derived neurotrophic factor (BDNF) is a mediator of neuronal survival and plasticity of dopaminergic, cholinergic, and serotonergic neurons in the central nervous system (CNF) [6]. BDNF is involved in usedependent plasticity mechanisms, such as long-term enhancement and learning, which may play an important role in neuropathology and the treatment of depression [7]. This theory is based mainly on the correlation between stress or antidepressant treatment and the decrease or increase in BDNF [8]. Brunoni AR et al. believed that blood $B D N F$ was associated with a depression response, and the $B D N F$ level in patients with depression was much lower than that observed in normal people: The greater the severity of the depressive symptoms, the lower the BDNF level in serum [9]. Tryptophan hydroxylase-2 (TPH2) gene is an important factor for the synthesis of 5-HT in the brain, the maintenance of normal 5-HT levels in the brain, and the maintenance of normal transmission by $5-\mathrm{HT}$ in the cortex [10]. Studies have shown that polymorphisms in the TPH-2 gene are associated with depression, and single nucleotide polymorphisms (SNPs) in the TPH2 gene are associated with major depression [11]. A meta-analysis of studies on the correlation between $T P H 2$ gene polymorphisms and depression found that all studies on TPH-2 rs7305115 were analyzed by subgroups of Asian countries and 
non-Asian countries. Among rs7305115, the GG genotype and G allele in Asian countries also increased the risk of depression [12].

Musculoskeletal disorders (MSDs) are due to occupational exposure risk factors (e.g., repeat operations, poor posture, physical loads, vibration, etc.), and can cause obvious damage to the musculoskeletal system. MDSs are associated with symptoms such as numbness, pain, and restricted movement, and these symptoms tend to last for more than 24 hours. After a period of rest, the patients may have been unable to return to work, and it is necessary to rule out other medical emergencies, physical disabilities, or illness sequelae, as the cause [13]. MSDs are one of the common types of occupational diseases that are found in almost every industry. Due to differences in the characteristics of industries and in the nature of various types of work, the prevalence of MSDs in different industries also varies substantially. MSDs are included in the category of occupational diseases in industrial developed countries, and it is becoming increasingly vital to address the prevention and treatment of MSDs. The World Health Organization (WHO) has shown continuous concern for this issue, encouraging a greater amount of research to be carried out on occupational diseases [14]. Studies have demonstrated that the number of cases of work-related MSDs accounts for more than $60 \%$ of the total cases of occupational diseases, and it is the main cause of absenteeism, disability, early retirement, and economic loss [15-16]. According to relevant research data from various countries, MSDs in the working population accounts for more than $50 \%$ of the total population [17-19], and the annual medical and compensation costs caused by MSDs reached more than 13-54 billion [20]. Crofford et al.[21] showed that psychological stress can directly cause physiological reactions, such as increased muscle tension, and these reactions may eventually induce musculoskeletal development. Work-related pressure can cause workers to unconsciously assume a forced body posture at work. Workers may not ensure that they get enough rest, and they may experience physical discomfort as a result of maintaining a static posture for a long time, which leads to greater musculoskeletal pressure.

At present, coal remains the core energy-type of the global energy system, and the global demand for coal will remain stable over the next five years. Therefore, in order to ensure the sustainable development of the coal industry, we must pay attention to the health problems of coal miners. The work environment of coal miners and the need to work in an environment that is hundreds of meters underground means that coal miners are subjected to large amounts of dust, noise, vibrations, and humidity, as well as factors that pose occupational hazards, such as poor posture. In addition, years of working in a poor environment have cause coal miners to develop pneumoconiosis, chronic obstructive pulmonary disease COPD, musculoskeletal disorders, and other diseases. Moreover, the underground coal mine environment is highly complex. Water, fire, gas, coal dust, and other factors threaten the safety and lives of coal miners, and as such, these workers are obliged to cope with substantial psychological pressures during their work. Thus far, most studies have investigated the status quo of musculoskeletal disorders, the mental health status, and influencing factors of coal miners, while few studies have analyzed the relationship between musculoskeletal disorders and mental health. However, there are few reports on the influence of the gene-environment interaction on the mental health of coal miners. Therefore, this study constructed a gene-environment interaction model using GMDR(0.9), and analyzed the relationship between musculoskeletal disorders, $B D N F$ gene, $T P H 2$ gene, and mental health, so as to provide a basis for relevant departments to take corresponding measures to improve the mental health of coal miners and improve their quality of life. 


\section{Methods}

\section{Study population and procedure}

This cross-sectional study was conducted from August 2018 to June 2019. According to the main production process of coal mines (i.e., a surface production system and underground production system), stratified cluster sampling was employed to carry out a questionnaire survey among coal miners with more than one year of work experience. Inclusion criteria: The participants who took part in this study were coal miners aged 18-60 years old who had worked for more than one year, volunteered to participate, and provided their written informed consent. Exclusion criteria: Miners who suffered from severe cognitive impairment or who had a previous history of dementia or mental illness were excluded. A total of 1,800 questionnaires were distributed, of which 1,675 were retrieved, with an effective recovery rate of $93.06 \%$. This research scheme was approved by the Ethics Committee of Xinjiang Medical University .

A total of $30 \%$ of the sample content was randomly selected as the experimental sample [22], and samples with substandard concentration and purity were eliminated for DNA extraction. Finally, 250 coal miners with psychological disorders were selected as the case group for this experimental study. According to the 1:1 matching principle, 250 coal miners, who did not suffer from any psychological disorder, were selected as the control group. The matching principle was: same sex, same unit, age \pm 2 years, and length of service \pm 2 years.

Measures

\section{Musculoskeletal disorders investigation}

Using the musculoskeletal disorders questionnaire that was jointly developed by Yang Lei et al. [23], the questionnaire was compiled according to the Nordic Musculoskeletal Survey, which divided the body into nine parts: the neck, shoulder, upper back, elbow, lower back, wrist, hip, knee, and foot. The respondents were asked whether they had experienced any discomfort in each part of their body over the past year, and if they had suffered from any discomfort, they were asked if such symptoms were resulted in work absenteeism. The questionnaire was compiled based on the national conditions of China and the research experience of domestic scholars, which was more suitable for the evaluation of MSDs among the Chinese population. The overall Cronbach's a coefficient of the questionnaire was 0.81 , showing good reliability and validity [24]. MSDs were determined by the criteria specified by the National Institute of Occupational Safety and Health (NIOSH) for work-related musculoskeletal injury in the United States. When symptoms of discomfort, such as pain, burning, numbness or tingling occur in various muscles and joints of the body, and the following conditions are met at the same time, it can be determined that this body part is affected by musculoskeletal disease [25]: (1) Unwell during the past year, (2) patients started to feel uncomfortable after undertaking the current job, (3) no previous accidents or sudden injuries, etc. (affected parts of discomfort), and (4) the symptoms of discomfort occurred every month or lasted for more than seven days.

\section{Mental health investigation}

In this study, the Symptom Checklist-90 (SCL-90) was used to measure mental health [26], which assessed the mental health status of individuals during a one-week period. The scale consists of 10 factors, including somatization, compulsion, interpersonal sensitivity, depression, anxiety, hostility, terror, paranoia, psychosis, 
and other items, and it includes a total of 90 items. The scoring method was based on a five-point Likert-type scale, and the score of each item was tabulated to determine the total score of the SCL-90, the higher the score, the poorer the mental health status. The criteria for identifying the presence of psychological disorders was as follows: total score $\geq 160$ points or $>2$ points for any factor [27]. This scale had good reliability and validity[28].

\section{Genotyping}

According to the related references and the use of the HapMap database (http://hapmap.ncbi.nlm.nih.gov/), this study referred to information concerning SNP genotypes in the Chinese Human Genome (CHB). The current internationally recognized gold standard was applied (i.e., r2 $=0.8, \mathrm{MAF}>15 \%$ standard) and Haploview software (http://www.broad.mit.edu/mpg) was used to select the target tag SNP sites. The SNP sites, which were finally screened out in this study, included the following: the BDNF gene rs6265 and Chinese genome-wide SNP genotype information with respect to rs10835210, TPH2 gene rs4570625, and rs4131347. The target fragment was amplified by polymerase chain reaction restriction fragment length polymorphism (PCR-RFLP), the PCR products were digested with specific endonucleases for SNP typing to detect the polymorphisms in rs6265, rs10835210, rs4570625, and rs4131347 of the BDNF gene extracted from whole blood DNA. Table 1.

Table 1. Primer sequences

\begin{tabular}{lll}
$\begin{array}{ll}\text { Primer } \\
\text { BDNF }\end{array}$ & \multicolumn{2}{c}{ Sequence } \\
\hline rs6265 & Forward & 5'-CTGCTTTCTCCCTACAGTTCCAC-3' \\
\hline & Reverse & 5'-CAAGTCTGCGTCCTTATTGTTTTCT-3' \\
\hline rs10835210 & Forward & 5'-GTGGGTAGACGCCAAAAC-3' \\
\hline & Reverse & 5'-GCCTGGAAACTGCCTTACT-3' \\
\hline TPH-2 & & \\
\hline rs4570625 & Forward & 5'-TTTTATGAAAGCCATTACACAT-3' \\
\hline & Reverse & 5'-TTCCACTCTTCCAGTTATTTTA-3' \\
\hline rs4131347 & Forward & 5'-TTGGTCCAGGGTTCACTCAT-3' \\
\hline & Reverse & 5'-TTGTGGCCAAGAAACTTTGG-3'
\end{tabular}

\section{Quality control}

Before carrying out the formal investigation, we conducted a small preliminary survey. The investigators were trained uniformly and have medical knowledge. After the respondents completed the questionnaire, it was collected immediately on-site. After the questionnaire was collected, the investigators uniformly numbered the questionnaires and checked the extent to which they had been completed. Questionnaires that contained less than $80 \%$ of the content were rejected. During the experiment, the reagent name was carefully checked, the reagent was added in strict accordance with the required dosage, and the experiment time was controlled in strict accordance with the instructions. Samples and reagents were properly stored to avoid degradation and 
cross-contamination. During the experiment, the experimental samples were numbered one by one to ensure the correspondence between the experimental samples and the epidemiological investigation samples.

\section{Statistical analysis}

The data were entered into the Epidata 3.0 database, SPSS version 21.0 software was used for the statistical analysis. T-tests were performed to compare the mean between the two groups, chi-squared tests were carried out to compare the rates, and unconditional logistic regression was used for multivariate analysis. The haploid analysis of gene loci was performed by SHEsis software. Generalized multi-factor dimensionality reduction (GMDR 0.9) software was used to construct and analyze gene-gene and gene-environment interaction models. MDR (3.0.2) software was used to draw tree diagrams of gene-gene and gene-environment interactions.

\section{Results}

\section{Comparison of SCL-90 factor scores of coal miners with the national norm in China}

Compared with the national norm[29], the SCL-90 scores of coal miners showed statistically significant differences $(P<0.05)$, except in the case of the interpersonal sensitivity factor $(P<0.05)$. The scores of other factors of coal miners were lower than the national norm, and the scores of other factors were higher than the national norm. Table 2

Table 2. SCL-90 scores of coal miners compared with domestic norms

\begin{tabular}{|lllll|}
\hline Variables & Coal miner $₫ n=1675 \rrbracket$ & Chinese norms $₫ n=1338 \rrbracket$ & $t$ & $P$ \\
\hline Somatization & $1.53 \pm 0.61$ & $1.37 \pm 0.48$ & 7.848 & $<0.001$ \\
\hline Compulsive Symptoms & $1.74 \pm 0.63$ & $1.62 \pm 0.58$ & 5.380 & $<0.001$ \\
\hline Interpersonal Sensitivity & $1.62 \pm 0.65$ & $1.65 \pm 0.61$ & -1.294 & 0.196 \\
\hline Depression & $1.58 \pm 0.65$ & $1.50 \pm 0.59$ & 3.496 & $<0.001$ \\
\hline Anxiety & $1.46 \pm 0.57$ & $1.39 \pm 0.43$ & 3.725 & $<0.001$ \\
\hline Hostility & $1.54 \pm 0.62$ & $1.48 \pm 0.56$ & 2.754 & 0.006 \\
\hline Fear & $1.34 \pm 0.52$ & $1.23 \pm 0.41$ & 6.325 & $<0.001$ \\
\hline Paranoia & $1.48 \pm 0.60$ & $1.43 \pm 0.57$ & 2.324 & 0.020 \\
\hline Psychosis & $1.41 \pm 0.54$ & $1.29 \pm 0.42$ & 6.674 & $<0.001$ \\
\hline Another Factors & $1.60 \pm 0.63$ & $1.65 \pm 0.61$ & -2.195 & 0.028 \\
\hline SCL-90 Total Score & $138.27 \pm 49.13$ & $129.96 \pm 38.76$ & 5.056 & $<0.001$ \\
\hline
\end{tabular}

\section{Mental health status of coal miners under different MSDs conditions}

The SCL-90 factor scores of coal miners with different MSDs disease conditions were compared, and the scores of all factors in the MSDs group were higher than those in the Non-MSDs group $(P<0.001)$. Table 3 
Table 3. Mental health status of coal mine workers under different MSDs

\begin{tabular}{|lllll|}
\hline Variables & Non-MSDs $₫ n=727 \rrbracket$ & MSDs $\triangle n=948 \rrbracket$ & $t$ & $P$ \\
\hline Somatization & $1.33 \pm 0.48$ & $1.68 \pm 0.66$ & -12.179 & $<0.001$ \\
\hline Compulsive Symptoms & $1.56 \pm 0.52$ & $1.88 \pm 0.67$ & -10.619 & $<0.001$ \\
\hline Interpersonal Sensitivity & $1.45 \pm 0.52$ & $1.75 \pm 0.72$ & -9.603 & $<0.001$ \\
\hline Depression & $1.39 \pm 0.53$ & $1.72 \pm 0.69$ & -10.865 & $<0.001$ \\
\hline Anxiety & $1.31 \pm 0.45$ & $1.58 \pm 0.62$ & -10.020 & $<0.001$ \\
\hline Hostility & $1.35 \pm 0.50$ & $1.68 \pm 0.67$ & -11.077 & $<0.001$ \\
\hline Fear & $1.23 \pm 0.43$ & $1.42 \pm 0.57$ & -7.451 & $<0.001$ \\
\hline Paranoia & $1.34 \pm 0.50$ & $1.59 \pm 0.65$ & -8.815 & $<0.001$ \\
\hline Psychosis & $1.27 \pm 0.43$ & $1.52 \pm 0.58$ & -9.631 & $<0.001$ \\
\hline Another Factors & $1.43 \pm 0.53$ & $1.74 \pm 0.66$ & -10.302 & $<0.001$ \\
\hline SCL-90 Total Score & $123.14 \pm 39.34$ & $149.88 \pm 52.63$ & -11.462 & $<0.001$ \\
\hline
\end{tabular}

\section{Hardy-Weinberg genetic balance test}

The genotype distribution frequency of the $B D N F$ gene and the $T P H 2$ gene was analyzed using the HardyWeinberg genetic balance test between the case group and the control group. There was no statistical significance in the distribution of the actual value and the expected value of $B D N F$ (rs6265, rs10835210) gene polymorphisms and TPH-2 (rs4570625, rs4131347) gene polymorphisms in the case group and the control group ( $P>0.05)$. Table 4

Table 4. Genetic locus Hardy-Weinberg genetic balance test 


\begin{tabular}{|c|c|c|c|c|c|c|c|c|c|}
\hline \multirow[t]{2}{*}{ Gene } & \multirow[t]{2}{*}{ Genotype } & \multicolumn{2}{|c|}{ Case group } & \multirow[t]{2}{*}{$x^{2}$} & \multirow[t]{2}{*}{$P$} & \multicolumn{2}{|c|}{ Control group } & \multirow[t]{2}{*}{$\chi^{2}$} & \multirow[t]{2}{*}{$P$} \\
\hline & & $\begin{array}{l}\text { Actual } \\
\text { value }\end{array}$ & $\begin{array}{l}\text { Expectation } \\
\text { values }\end{array}$ & & & $\begin{array}{l}\text { Actual } \\
\text { value }\end{array}$ & $\begin{array}{l}\text { Expectation } \\
\text { values }\end{array}$ & & \\
\hline \multirow[t]{8}{*}{$B D N F$} & rs 6265 & & & & & & & & \\
\hline & AA & 65 & 71.3 & \multirow[t]{3}{*}{2.555} & \multirow[t]{3}{*}{0.110} & 50 & 52.9 & \multirow[t]{3}{*}{0.545} & \multirow[t]{3}{*}{0.46} \\
\hline & $A G$ & 137 & 124.4 & & & 130 & 124.2 & & \\
\hline & GG & 48 & 54.3 & & & 70 & 72.9 & & \\
\hline & \multicolumn{9}{|l|}{ rs10835210 } \\
\hline & AA & 27 & 32.8 & \multirow[t]{3}{*}{2.489} & \multirow[t]{3}{*}{0.115} & 16 & 20.7 & \multirow[t]{3}{*}{2.134} & \multirow[t]{3}{*}{0.144} \\
\hline & $\mathrm{AC}$ & 127 & 115.5 & & & 112 & 102.5 & & \\
\hline & $\mathrm{CC}$ & 96 & 101.8 & & & 122 & 126.7 & & \\
\hline \multirow{8}{*}{$\begin{array}{l}\text { TPH- } \\
2\end{array}$} & rs4570625 & & & & & & & & \\
\hline & GG & 76 & 82.9 & \multirow[t]{3}{*}{3.234} & \multirow[t]{3}{*}{0.072} & 58 & 60.5 & \multirow[t]{3}{*}{0.405} & \multirow[t]{3}{*}{0.524} \\
\hline & GT & 136 & 122.1 & & & 130 & 125.0 & & \\
\hline & TT & 38 & 44.9 & & & 62 & 64.5 & & \\
\hline & \multicolumn{9}{|l|}{ rs4131347 } \\
\hline & $\mathrm{CC}$ & 70 & 68.6 & \multirow[t]{3}{*}{0.118} & \multirow[t]{3}{*}{0.731} & 77 & 71.3 & \multirow[t]{3}{*}{2.107} & \multirow[t]{3}{*}{0.147} \\
\hline & CG & 122 & 124.7 & & & 113 & 124.4 & & \\
\hline & GG & 58 & 56.6 & & & 60 & 54.3 & & \\
\hline
\end{tabular}

\section{Genotypes and allele frequencies of $B D N F$ and $T P H 2$}

Except for TPH2 rs4131347 gene polymorphism, the genotype and allele distribution frequency of BDNF (rs6265, rs10835210) and TPH-2 rs4570625 gene polymorphisms showed statistical significance between the case group and the control group $(P<0.05)$. The results suggested that rs 6265 and rs 10835210 of the $B D N F$ gene and rs 4570625 of the TPH2 gene were associated with the occurrence of mental disorders. Table 5

Table 5. Distribution frequency of $B D N F, T P H-2$ genotypes, and alleles in the case group and control group 


\begin{tabular}{|c|c|c|c|c|c|}
\hline Gene & Genotype/allele & Case group $\varangle \% \bigotimes$ & Control group $₫ \% \rrbracket$ & $\chi^{2}$ & $P$ \\
\hline \multirow[t]{5}{*}{$B D N F$ rs 6265} & $\mathrm{AA}$ & $65 \rrbracket 26.0 \rrbracket$ & $50 \rrbracket 20.0 \rrbracket$ & \multirow[t]{3}{*}{6.242} & \multirow[t]{3}{*}{0.044} \\
\hline & $A G$ & $137 \rrbracket 54.8 \rrbracket$ & $130 \rrbracket 52.0 \rrbracket$ & & \\
\hline & GG & $48 \rrbracket 19.2 \rrbracket$ & $70 \rrbracket 28.0 \rrbracket$ & & \\
\hline & $A$ & 267区53.4区 & $230 \rrbracket 46.0 \rrbracket$ & \multirow[t]{2}{*}{5.476} & \multirow[t]{2}{*}{0.019} \\
\hline & $\mathrm{G}$ & $233 \rrbracket 46.6 \rrbracket$ & $270 \rrbracket 54.0 \rrbracket$ & & \\
\hline \multirow[t]{5}{*}{$B D N F$ rs 10835210} & $\mathrm{AA}$ & $27 \rrbracket 10.8 \rrbracket$ & $16 \rrbracket 6.4 \rrbracket$ & \multirow[t]{3}{*}{6.856} & \multirow[t]{3}{*}{0.032} \\
\hline & $\mathrm{AC}$ & $127 \rrbracket 50.8 \rrbracket$ & $112 \varangle 44.8 \rrbracket$ & & \\
\hline & $\mathrm{CC}$ & $96 \rrbracket 38.4 \rrbracket$ & $122 \rrbracket 48.8 \rrbracket$ & & \\
\hline & $A$ & $181 \rrbracket 36.2 \rrbracket$ & 144『28.8\ & \multirow[t]{2}{*}{6.240} & \multirow[t]{2}{*}{0.013} \\
\hline & C & $319 \rrbracket 63.8 \rrbracket$ & $356 ه 71.2 \rrbracket$ & & \\
\hline \multirow[t]{5}{*}{$T P H-2$ rs4570625 } & GG & 76ه30.4区 & $58 \rrbracket 23.2 \rrbracket$ & \multirow[t]{3}{*}{8.313} & \multirow[t]{3}{*}{0.016} \\
\hline & GT & 136ه54.4】 & 130ه52.0区 & & \\
\hline & TT & $38 \otimes 15.2 \rrbracket$ & $62 \rrbracket 24.8 \rrbracket$ & & \\
\hline & G & $288 \llbracket 57.6 \rrbracket$ & $246 \rrbracket 49.2 \rrbracket$ & \multirow[t]{2}{*}{7.089} & \multirow[t]{2}{*}{0.008} \\
\hline & $\mathrm{T}$ & $212 \rrbracket 42.4 \rrbracket$ & $254 \llbracket 50.8 \rrbracket$ & & \\
\hline \multirow[t]{5}{*}{ TPH-2 rs4131347 } & $\mathrm{CC}$ & $70 \rrbracket 28.0 \rrbracket$ & $77 ه 30.8 \rrbracket$ & \multirow[t]{3}{*}{0.712} & \multirow[t]{3}{*}{0.701} \\
\hline & CG & $122 \rrbracket 48.8 \rrbracket$ & $113 \rrbracket 45.2 \rrbracket$ & & \\
\hline & GG & $58 \rrbracket 23.2 \rrbracket$ & $60 \rrbracket 24.0 \rrbracket$ & & \\
\hline & $\mathrm{C}$ & $262 \rrbracket 52.4 \rrbracket$ & $267 \rrbracket 53.4 \rrbracket$ & \multirow[t]{2}{*}{0.100} & \multirow[t]{2}{*}{0.751} \\
\hline & $G$ & $238 \rrbracket 47.6 \rrbracket$ & $233 \rrbracket 46.6 \rrbracket$ & & \\
\hline
\end{tabular}

\section{Correlation analysis of $B D N F$ gene haplotypes and mental disorders}

Based on linkage-disequilibrium across gene loci, we determined the following: the $B D N F$ gene rs6265 locus and rs 10835210 coefficient $D^{\prime}=0.070, R 2=0.002$, Global chi-square $=35.690$, and genotype distribution frequency $>0.03$. The results suggested that the linkage imbalance between rs 6265 and rs 10835210 was not obvious. Four haplotypes (A-A, A-C, G-A, and G-C) were constructed using the software. The distribution of A-A haplotypes and G-A haplotypes was statistically different between the case group and the control group $(P<0.05)$, and A-A haplotypes were identified as the risk factors for mental disorders, while G-A haplotypes were protective factors for mental disorders. Figure 1, Table 6

Table 6. Analysis of the association between haplotypes of BDNF gene SNPs and mental disorders 


\begin{tabular}{|c|c|c|c|c|c|}
\hline Haplotype & Case group $\mathbb{\otimes \square}$ & Control group $₫ \% \bigotimes$ & $\chi^{2}$ & $P$ & $O R \otimes 95 \% C l$ \\
\hline A-A & $105.82 \varangle 21.2 \rrbracket$ & $40.82 \llbracket 8.2 \rrbracket$ & 33.760 & $<0.001$ & $3.020 \rrbracket 2.054 \sim 4.440 \rrbracket$ \\
\hline$A-C$ & 161.18ه32.2】 & $189.18 \rrbracket 37.8 \rrbracket$ & 3.444 & 0.064 & $0.782 \bowtie 0.602 \sim 1.014 \rrbracket$ \\
\hline G-A & $75.18 \rrbracket 15.0 \rrbracket$ & 103.18邓20.6邓 & 5.348 & 0.021 & $0.681 \rrbracket 0.491 \sim 0.944 \rrbracket$ \\
\hline G-C & 157.82囚31.6囚 & 166.82囚33.4囚 & 0.370 & 0.543 & $0.921 \rrbracket 0.707 \sim 1.200 \rrbracket$ \\
\hline
\end{tabular}

\section{Correlation analysis of TPH2 gene haplotypes and mental disorders}

The results showed the following: The linkage-disequilibrium coefficient $D^{\prime}=0.161, R 2=0.020$, Global chisquare $=8.084$, and the genotype distribution frequency was $>0.03$ for $T P H 2$ gene rs 4570625 and rs 4131347 . The results suggested that the linkage-disequilibrium between rs 4570625 and rs 4131347 was not obvious. The software constructed G-C, G-G, T-C, and T-G haplotypes. The distribution of G-C haplotypes and T-C haplotypes was statistically different between the case group and the control group $(\mathrm{P}<0.05)$, and $\mathrm{T}-\mathrm{C}$ haplotypes were a risk factor for mental disorders, while G-C haplotypes were a protective factor for mental disorders. Figure 2 , Table 7

Table 7. Analysis of the association between haplotypes of TPH-2 gene SNPs and mental disorders

\begin{tabular}{|c|c|c|c|c|c|}
\hline Haplotype & Case group $₫ \% \bigotimes$ & Control group $\varangle \%$ & $\chi^{2}$ & $P$ & OR刃95\%Cl \\
\hline G-C & $110.00 \otimes 22.0 \rrbracket$ & $137.71 \rrbracket 27.5 \rrbracket$ & 4.120 & 0.042 & $0.742 \varangle 0.556 \sim 0.990 \rrbracket$ \\
\hline G-G & $136.00 \rrbracket 27.2 \rrbracket$ & $150.29 \llbracket 30.1 \rrbracket$ & 0.999 & 0.317 & $0.869 \varangle 0.661 \sim 1.144 \rrbracket$ \\
\hline $\mathrm{T}-\mathrm{C}$ & $157.00 \rrbracket 31.4 \rrbracket$ & $124.29 \llbracket 24.9 \rrbracket$ & 5.292 & 0.021 & $1.384 \rrbracket 1.049 \sim 1.825 \rrbracket$ \\
\hline T-G & $97.00 \rrbracket 19.4 \rrbracket$ & $87.71 \otimes 17.5 \rrbracket$ & 0.573 & 0.449 & $1.131 \rrbracket 0.822 \sim 1.558 \rrbracket$ \\
\hline
\end{tabular}

\section{GMDR constructs the geneenvironment interaction model}

GMDR software was used to analyze the interaction of BDNF gene, TPH2 gene, and MSDs gene on psychological disorders. The cross-consistency coefficient of the interaction model between MSDs and BDNF gene rs6265, and $T P H 2$ gene rs 4570625 was the highest (10/10). The accuracy of the training set was 0.66 and the accuracy of the test set was 0.62 , which was statistically significant $(P=0.011)$. The results showed that MSD s interacted with BDNF rs6265 and TPH-2 rs4570625. Table 8, Figure 3. The tree diagram showed that there was a strong positive interaction between TPH2 gene rs4570625 and MSDs. Figure 4.

Table 8. GMDR: A gene-environment interaction model 


\begin{tabular}{|c|c|c|c|c|c|}
\hline \multirow[t]{2}{*}{ Model } & \multicolumn{2}{|l|}{ Precision } & \multicolumn{2}{|c|}{ Sign test } & \multirow{2}{*}{$\begin{array}{l}\text { Cross validation } \\
\text { Consistency coefficient }\end{array}$} \\
\hline & training set & test set & $\chi^{2}$ & $P$ & \\
\hline MSDs & 0.56 & 0.52 & 6 & 0.377 & $7 / 10$ \\
\hline TPH-2 rs4570625*MSDs & 0.62 & 0.60 & 10 & 0.001 & $10 / 10$ \\
\hline$B D N F \mathrm{rs} 6265^{\star} T P H-2$ rs $4570625^{\star} \mathrm{MSDs}$ & 0.66 & 0.62 & 9 & 0.011 & $10 / 10$ \\
\hline
\end{tabular}

Mental disorders were taken as the dependent variable. Then, combined with the GMDR results, MSDs, MSDs $*_{r s 4570625}$, and MSDs * ${ }^{2} 6265{ }^{*}$ rs4570625 were introduced into the equation for further logistic regression analysis of gene-environment interactions. The results showed that rs $4570625(\mathrm{GG}) \star \mathrm{MSDs}$ $(\mathrm{OR}=6.000,95 \% \mathrm{Cl}: 1.723-20.889) \square \mathrm{rs} 4570625(\mathrm{GT}){ }^{*} \mathrm{rs} 6265(\mathrm{AA}) * \mathrm{MSD} s(\mathrm{OR}=12.444,95 \% \mathrm{Cl}: 3.031-51.079) \square$ rs4570625(GT)*rs6265(AG)*MSDs(OR=5.765,95\%Cl:1.530-21.718). Gene-environment interactions are risk factors for mental disorders. Figure 5.

\section{Discussion}

The results of this study showed that the coal miners' SCL-90 scores were higher than the national norm, and the mental health of coal miners was poor. Coal miners work in a difficult environment, their work place is far away from the city, the climatic conditions are harsh, and there is a lack of recreational facilities. Therefore, it is easy to understand that these workers have no outlet to vent work-related pressure and negative emotions, which may easily cause them to develop psychological problems over the long run [30]. At the same time, coal mine work is high-risk, and workers are obliged to bear huge risks. On the one hand, the underground work environment is dark, the air is humid, and the work is made more difficult by the harm that is cause by noise and dust. Lei et al [31] believed that the longer coal miners were exposed to dust, the lower their quality of life and the poorer their mental health. Lu et al.[32] utilized propensity score analysis to demonstrate that occupational hazards, such as asbestos dust, benzene, and noise in the work environment, adversely affect the physical and mental health of workers, causing physical and psychological harm to workers. On the other hand, accidents, such as gas poisoning, an explosion, flooding, a cave-in, gas ejection, and fire, pose threats to the safety and lives of the workers, as these events can happen at any time during their work, so the miners are subject to immense psychological pressure, which affects their mental health [33]. Although the development of coal mining technology has improved the mechanization of underground operations and greatly reduced the workload of workers, new requirements have also been put forward for the knowledge structure of underground workers. Coal miners are generally poorly educated and lack the time and energy to enhance their knowledge or improve their working skills. Therefore, they feel that they lack job security and are prone to anxiety. Han et al. [34] investigated the mental health status of 642 coal miners from six coal mining companies in six provinces in China and found that the mental health status of coal miners was poor, especially among older people, those with low incomes, and low education level.

MSDs patients scored higher on the SCL-90 than workers who did not suffer from MSDs. The reason for this may be that miners work at narrow coal faces for a long period of time, which places great physical and psychological pressure on miners, and thus, leads to physical discomfort, such as back pain and muscle pain, 
as well as adverse psychological emotions. Liu Yujiao [35]believed that underground work, especially underground mining work, means that coal miners are subjected to a high labor intensity, narrow coal faces, and high physical demands. High work-loads over the long-term means that miners are likely to experience muscle strain, problems with the neck, shoulder, waist, and limbs, and other physical symptoms. Such physical discomfort can easily bring about psychological changes in the workers. If a negative mood cannot be alleviated, this will further aggravate any physical discomfort. Moreover, physical discomfort that arises as a response to psychological stress can further exacerbate the mental health problems of workers. Studies have proposed that there is a bidirectional association between MSDs and psychological factors, i.e., a feedback loop, which harms the physical and mental health of workers [36]. Cho et al. [37] investigated 2,037 subway workers and found that workers with high scores on depression, anxiety, and stress scales, especially among shift workers, showed a significant increase in the prevalence of musculoskeletal symptoms. The management of musculoskeletal symptoms should consider both ergonomic and mental health factors. The occurrence of MSDs is mainly related to physical loads, static loads, poor posture, and repetitive tasks, etc. With the deepening of research, greater attention is gradually being paid to the influence of social psychological factors on MSDs.

$B D N F$ gene polymorphisms affect the $B D N F$ transport and secretion process, thereby regulating the occurrence and development of mental diseases and changes in cognitive function. [38]. It has been found that the BDNF rs6265 gene polymorphism can affect synaptic transmission of NMDA receptors in the hippocampus and amygdala, increasing depressive and anxiety-related behavior [39, 40], which highlights how BDNF plays an important role in the development and treatment of neuropsychiatric disorders [41]. The rs 4570625 polymorphism, located in the promoter region, is the most extensive polymorphic locus in studies on the association between the $T P H 2$ gene and psychological diseases [42]. At present, the research results of domestic and foreign scholars on the rs 4570625 locus are not consistent. Gao found that, compared with individuals with the homozygous T allele at rs4570625, G allele carriers (GG or GT) had a higher incidence of depression, schizophrenia, suicide, and other diseases [43]. Similar results have been obtained in many studies $[44,14]$. Some studies have also pointed out that no relationship was found between $T P H 2$ rs 4570625 gene polymorphism and psychological disorders [45]. This study conducted a haplotype analysis of BDNF gene (rs6265, rs10835210) and TPH-2 gene (rs4570625, rs4131347). The findings revealed an associated between the occurrence of psychological disorders and rs6265 and rs10835210 in BDNF gene, as well as rs4570625 in $T P H 2$ gene. The $B D N F$ gene A-A haplotype is a risk factor for psychological disorders, and the G-A haplotype is a protective factor for psychological disorders. The T-C haplotype of the TPH2 gene is a risk factor for psychological disorders, while the G-C haplotype is a protective factor for psychological disorders. GMDR was used to construct the gene-environment interaction model, and the results suggested that there were interactions between MSDs and BDNF gene rs6265 and TPH2 gene rs4570625. A strong positive interaction was detected between TPH-2 gene rs 4570625 and MSDs. Combined with the GMDR results, further logistic regression analysis of gene-environment interaction showed that the interaction between BDNF(rs6265), TPH2 (rs4570625), and MSDs was a risk factor for mental disorders.

\section{Conclusion}

MSDs, the $B D N F$ gene, and the $T P H-2$ gene were identified as influencing factors with respect to the mental health of coal miners. Gene-environment interactions have also been found to influence the mental health of 
coal miners. It is suggested that employers should improve the work environment of such workers, shorten their working time, consider the mental health of workers, and ensure that psychological counseling is provided to workers with mental health problems in a timely manner, so as to improve the mental health and working ability of the workers, as well as their quality of life. Some shortcomings of this study included the following: (1) This study involved a cross-sectional survey, so it was difficult to infer any causal relationships. A cohort study will be carried out to further clarify the relationship between the MSDs, the BDNF gene, and the TPH-2 gene. (2) The object of this survey was limited to only coal miners in one area, so the conclusions reached should be extrapolated with caution. In the future, the sample size will be expanded to investigate the research subjects in multiple regions. (3) The measurement indicators of mental health are relatively single, so the measurement tools should be appropriately increased to ensure the accuracy of the measurement.

\section{Declarations}

\section{Acknowledgements}

The authors thank the study participants.

\section{Authors' contributions}

T.J., X.L., and J.L. conceived and designed the study, T.J., X.L., and Q.X. contributed to acquisition, analysis, and interpretation of data, X.L., T.J., Q.X. and J.L. were involved in drafting the manuscript and revising it for important intellectual content. All authors have read and agreed to the published version of the manuscript.

\section{Funding}

This study was funded by the Nature Science Foundation of Xinjiang autonomous region (Grant No.:2018D01C146).

\section{Availability of data and materials}

The datasets used and/or analysed during the current study are available from the corresponding author on reasonable request.

\section{Declarations Ethics approval and consent to participate}

The study was approved by the ethics committee of Xinjiang Medical University. Informed consent of all participate was obtained for this study.

\section{Consent for publication}

Not applicable.

\section{Competing interests}

The authors declare no conflict of interest.

\section{Statements}


The study protocol is performed in accordance with the relevant guidelines.

\section{References}

1. Lever N, Mathis E, Mayworm A. School Mental Health Is Not Just for Students: Why Teacher and School Staff Wellness Matters. Rep Emot Behav Disord Youth. 2017 Winter,17(1):6-12.

2. Wood JD, Watson AC. Improving police interventions during mental health-related encounters: Past, present and future. Policing Soc. 2017,27:289-299.

3. McFarland DC, Hlubocky F, Riba M. Update on Addressing Mental Health and Burnout in Physicians: What Is the Role for Psychiatry? Curr Psychiatry Rep. 2019 Oct 15,21(11):108.

4. Fu A, Liu B, Jiang Y, Zhao J, Zhang G, Liu J. A Mental Health Survey of Different Ethnic and Occupational Groups in Xinjiang, China. Int J Environ Res Public Health. 2017 Jan 5,14(1):46.

5. Merikangas KR, Merikangas AK. Harnessing Progress in Psychiatric Genetics to Advance Population Mental Health. Am J Public Health. 2019 Jun,109(S3):S171-S175.

6. Li WL,Cai HH,Wang B,et al.Chronic fluoxetine treatment improves is chemia-induced spatial cognitive deficits through increasing hippocampal neurogenesis after stroke[J]. J Neurosci Res:2009,87: 112 -122区

7. Russo-Neustadt AA, et al. Physical activity and antidepressant treatment potentiate the expression of specific brain-derived neurotrophic factor transcriptsin the rat hippocampus[J].euroscience. 2000,101(2):305-12.

8. Martinowich $\mathrm{K}$, et al. New insights into BDNF function in depression and anxiety[J].Nat Neurosci. 2007 Sep,10(9):1089-93.

9. Li L. Study on the change of serum CRP, BDNF and trace elements of patients with depression (in Chinese) [J]. China Mod Med, 2014,Mar:5(2):1124-26.

10. Tao S, Chattun MR, Yan R, Geng J, Zhu R, Shao J, Lu Q, Yao Z. TPH-2 Gene Polymorphism in Major Depressive Disorder Patients With Early-Wakening Symptom. Front Neurosci. 2018 Nov 15,12:827.

11. Mei F, Wu Y, Wu J. The Relationship Between Tryptophan Hydroxylase-2 Gene with Primary Insomnia and Depressive Symptoms in the Han Chinese Population. Balkan Med J. 2018 Nov 15,35(6):412-416.

12. Su Qiao, Wang Wenjuan, Guo Zhiwang, Li Zixuan, Wang Bingshuang, Ma Ning. Updated Meta-analysis of studies on the association between TPH2 gene polymorphism and depression[J].Chinese Journal of Misdiagnostics,2019,14(08):367-372.(In Chinese)

13. Pham M T, Rajic A, Greig J D, et al. A scoping review of scoping reviews: advancing the approach and enhancing the consistency[J]. Res Synth Methods, 2014, 5(4):371-385.

14. Wang ZhongxuखResearch progress of work-related musculoskeletal disorders and their assessment methods[J]区Chinese Journal of Industrial Medicine,2016,29(4):2438(In Chinese)

15. HEALTH AND SAFETY EXECUTIVE. Work-related musculoskeletal disorders (WRMSDs) statistics [S/OL]. (2016-11) [2016-12-22].http://www.hse.gov.uk/statistics/causdis/musculoskeletal/index.htm.

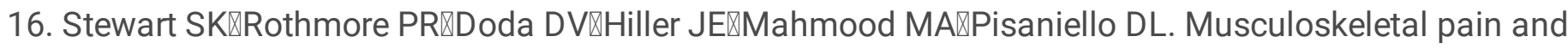
discomfort and associated worker and organizational factors: a cross-sectional study. Work. 2014,48(2):261-71. doi: 10.3233/WOR-131622.

Page 14/19 
17. Daneshmandi H,Kee D,Kamalinia An ergonomic intervention to relieve musculoskeletal symptoms of assembly line workers at an electronic parts manufacturer in Iran[J].Work,2018,61(4):515-521.

18. Mozafari A $₫$ Vahedian M $₫$ Mohebi S $₫$ Najafi M. Work-related musculoskeletal disorders in truck drivers and official workers. Acta Med Iran. 2015 Jul,53(7):432-8.

19. Yasobant, Sandul, Rajkumar, Paramasivan. Work-related musculoskeletal disorders among health care professionals: A cross-sectional assessment of risk factors in a tertiary hospital, India[J]. Indian Journal of Occupational \& Environmental Medicine, 18(2):75.

20. BHATTACHARYA A. Costs of occupational musculoskeletal disorders (MSDs) in the United States[J]. Int J Ind Ergonom, 2014, 44 (3) :448-454.

21. CROFFORD L J.Psychological aspects of chronic musculoskeletal pain[J]. Best Pract Res Clin Rheumatol,2015,29 (1): 147-155.

22. Wu Wenfeng. Epidemiological investigation of occupational stress and hypertension in desert oil workers and the interaction of susceptibility genes[D]. Urumqi: Xinjiang Medical University, 2019. (In Chinese)

23. Yang Lei,Wang Sheng, Hildebrandt VH, et al. Introduction to the Musculoskeletal Disorder Questionnaire[J]. Industrial Health and Occupational Diseases, 2009, 35(1): 25-31.(In Chinese)

24. Du Weiwei,Wang Sheng,Wang Jianxin,et al. Reliability and validity evaluation of the musculoskeletal disorders questionnaire[J]. Chinese Journal of Industrial Hygiene and Occupational Diseases, 2012, 30(5): 335-338. (In Chinese)

25. Neville Stanton, Alan Brookhuis, Eduardo Salas,et al. Handbook of human factors and ergonomics methods[M]. NewYork:CRC Press LLC, 2005:2-16.

26. Wang Xiangdong,Wang Xilin,Ma Hong.Manual of mental health rating scales[M]. Beijing: Chinese Journal of Mental Health, 1999:31-35. (In Chinese)

27. Ning Li, Lian Yulong, Liu Jiwen,et al. Establishment of Symptom Self-Rating Scale Norm in Part of Han Nationality in Xinjiang[J]. China Occupational Medicine, 2012, 39(1):8-12. (In Chinese)

28. Chen Shulin,Li Lingjiang. Comparison of SCL-90 reliability and validity test and norm[J].Chinese Journal of Nervous and Mental Diseases2003,29(5):323-327. (In Chinese)

29. Zhang Zuoying,Dai Dezhen,Lai Xianghui,Jiang Zheng ,Chen Qiuhui,Chi Hongcheng.Investigation and analysis of mental health status of occupational population in factories and enterprises in Luohu District, Shenzhen[J].Practical Preventive Medicine,2002(02):188-190. (In Chinese)

30. Yao Jian,Xiao Yuqing,Yong Xianting. Investigation on occupational stress and mental health of 491 coal miners[J].Journal of Xinjiang Medical University,2020,43(05):659-663. (In Chinese)

31. Han L, Li Y, Yan W, Xie L, Wang S, Wu Q, Ji X, Zhu B, Ni C. Quality of life and influencing factors of coal miners in Xuzhou, China. J Thorac Dis. 2018 Feb, 10(2):835-844.

32. Lu Y, Zhang Z, Yan H, Rui B, Liu J. Effects of Occupational Hazards on Job Stress and Mental Health of Factory Workers and Miners: A Propensity Score Analysis. Biomed Res Int. 2020 Aug 21,2020:1754897.

33. Liu Yujiao,Liu Jian,Zhu Baoyan.Mental health status of underground coal mine workers in China from 2007 to 2014[J].Journal of Safety and Environment,2018,18(01):176-181. (In Chinese)

34. Han S, Chen H, Harris J, Long R. Who Reports Low Interactive Psychology Status? An Investigation Based on Chinese Coal Miners. Int J Environ Res Public Health. 2020 May 15,17(10):3446. 
35. Liu Yujiao. Study on mental health of coal miners and its influencing factors[D].Liaoning Technical University,2018. (In Chinese)

36. Revankar VD, Chakravarthy Y, Naveen S, Selvan AS, Ganapathy A, Prasad AS. Musculoskeletal Disorders and Mental Health-related Issues as Occupational Hazards among Dental Practitioners in Salem City: A Cross-sectional Study. J Pharm Bioallied Sci. 2017 Nov,9(Suppl 1):S228-S230.

37. Cho YS, Park JB, Kim S, Lee K. Repeated measures study of the association between musculoskeletal symptoms and mental health in subway workers. Ind Health. 2019 Nov 29,57(6):721-731.

38. Pang Jianyue. Association analysis of BDNF, NOSL single nucleotide polymorphism and depression[D]. Zhengzhou: Zhengzhou University, 2014. (In Chinese)

39. McGregor NW, Dimatelis JJ, Van PJ, et al. A translational approach to the genetics of anxiety disorders[J]. Behavioural brain research, 2018, 341: 91-97.

40. Zhou Yingyong,Wang Saiying,Yang Mi, et al. Correlation analysis of BDNF gene polymorphism and postpartum depression in women with cesarean section[J]. Medical Journal of Chinese People's Liberation Army, 2017, 42(06): 538-544. (In Chinese)

41. Ryan KM, Dunne R, McLoughlin DM. BDNF plasma levels and genotype in depression and the response to electroconvulsive therapy[J]. Brain stimulation, 2018, 11(5): 1123-1131.

42. Wu JZ, Sinsel EW, Gloekler DS, et al. Inverse dynamic analysis of the biomechanics of the thumb while pipetting: A case study[J]. Medical engineering \& physics, 2012, 34(6): 693-701.

43. Gao J, Pan Z, Jiao Z, et al. TPH2 gene polymorphisms and major depression a meta analysis[J]. PloS one, 2012, 7(5): e36721.

44. Xu XM, Ding M, Pang H, et al. TPH2 gene polymorphisms in the regulatory region are associated with paranoid schizophrenia in northern Han Chinese[J]. Genetics and molecular research, 2014, 13(1): 14971507.

45. Long MH, Johnston V, Bogossian FE. Helping women but hurting ourselves, Neck and upper back musculoskeletal symptoms in a cohort of Australian Midwives[J]. Midwifery, 2013, 29(4): 359-367.

\section{Figures}


㟧

1

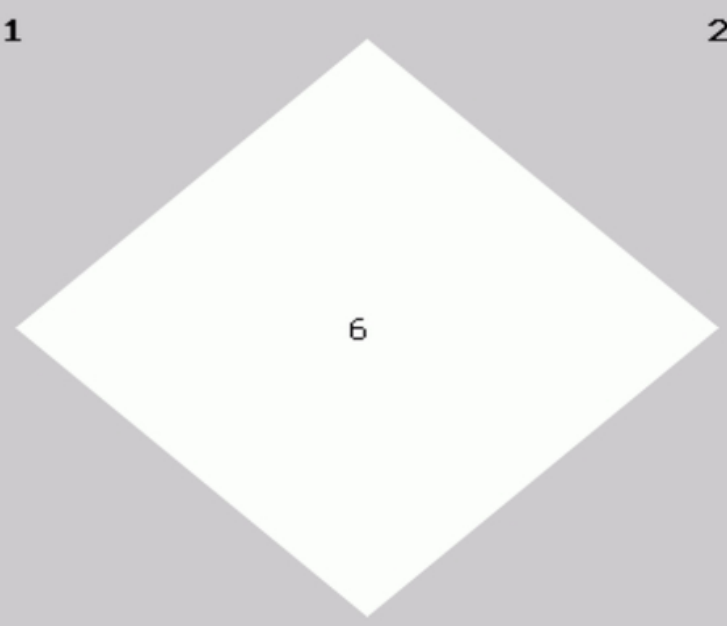

㟧

芯

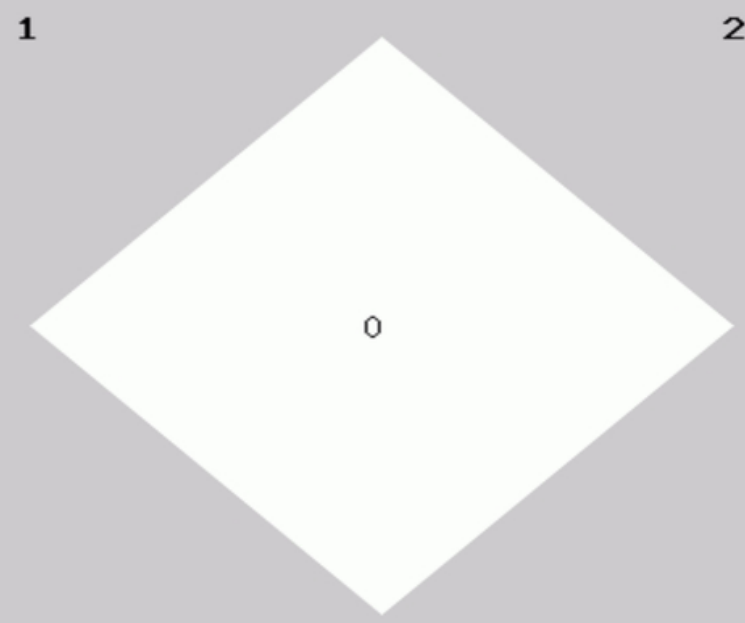

2

1

(2)

\section{Figure 1}

BDNF linkage imbalance analysis left: D' test, right: r2 test
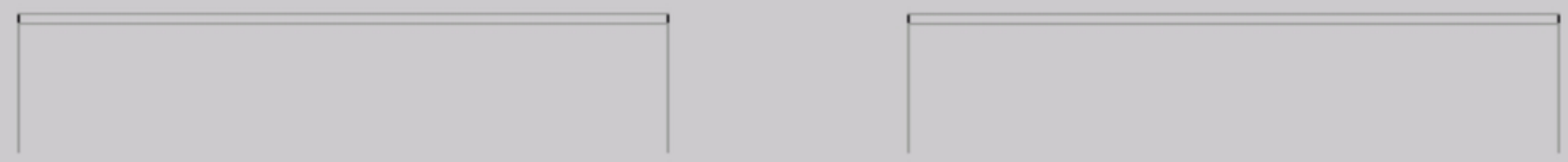

$\stackrel{\text { ஸे }}{\text { के }}$

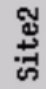

荧

芯

1

2

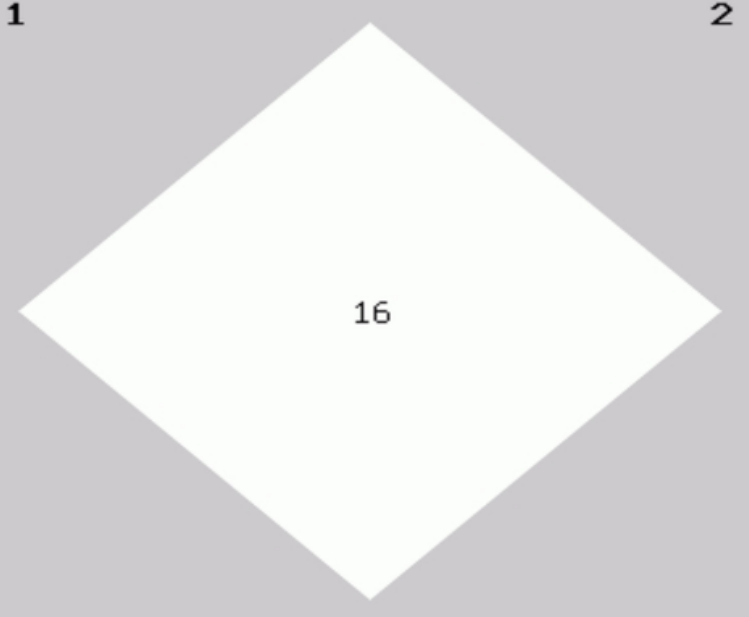




\section{MSDs}

0

BDNFrs6265

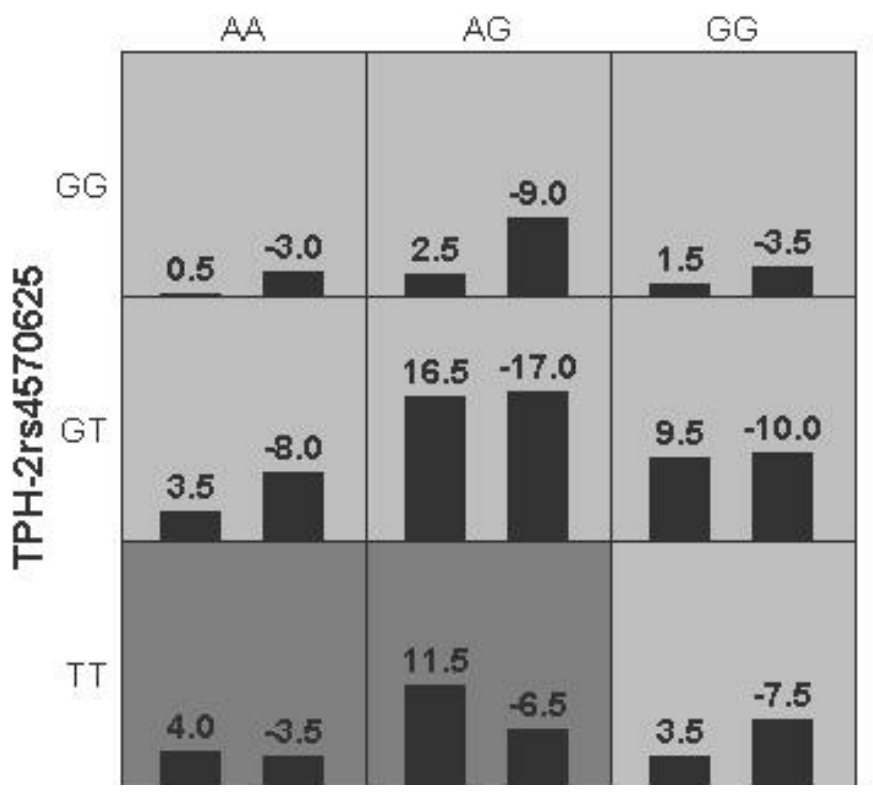

BDNFrs6265

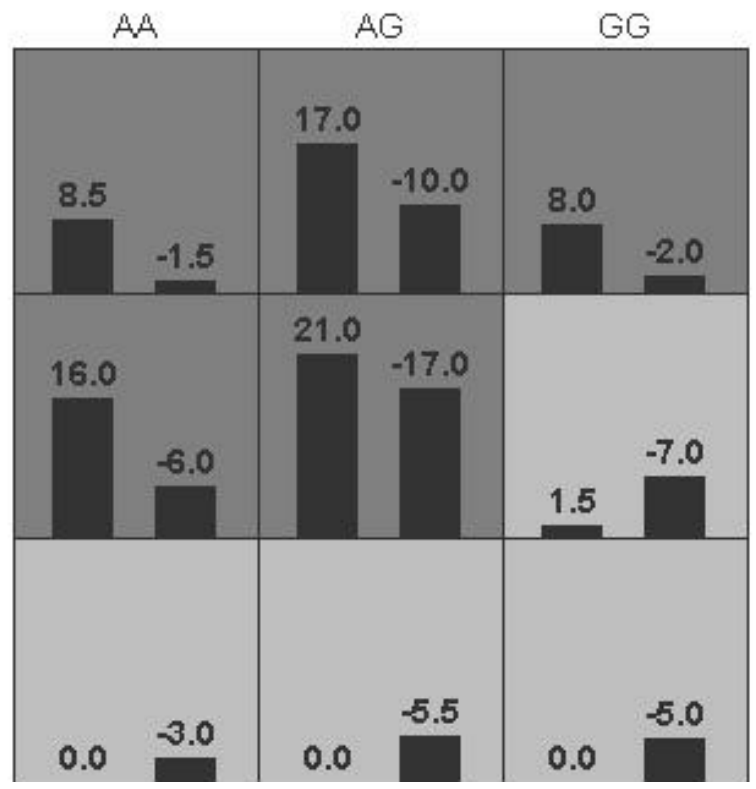

\section{Figure 3}

Gene-environment interaction model Note: The dark gray grid and the light gray grid represent high-risk and low-risk combinations, respectively. The left and right columns in the grid represent the case group and control group scores, respectively.

BDNFrs6265 TPH-2rs4570625 MSDs
Positive interaction

Negative interaction

\section{Figure 4}

Gene-environment interaction model 


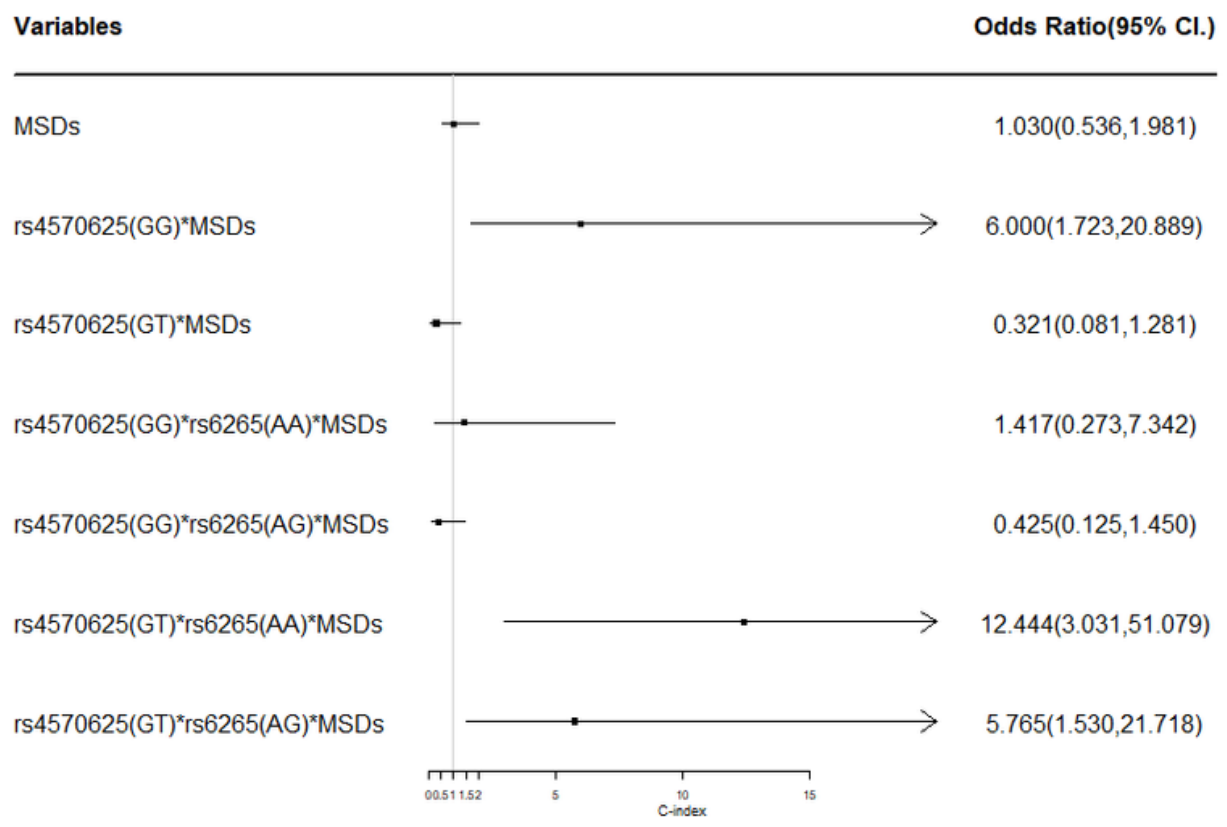

\section{Figure 5}

A logistic regression analysis of the impact of the gene-environment interaction on mental health 